\title{
Pelatihan Penggunaan Aplikasi Editing Foto Guna Mendukung Pelestarian Budaya Kelompok Musik Saronen
}

\author{
Ardy Januantoro ${ }^{1}$, Mohammad Insan Romadhan ${ }^{2}$ \\ Universitas 17 Agustus 1945 Surabaya $^{1}$, Universitas 17 Agustus 1945 Surabaya $^{2}$ \\ ardyjanuantoro@untag-sby.ac.id ${ }^{1}$, insanromadhan@untag-sby.ac.id ${ }^{2}$
}

\begin{abstract}
Abstrak
Indonesia memiliki anugerah besar dalam hal kekayaan budayanya, Tercatat sebanyak 8065 budaya yang dimiliki oleh Indonesia. Oleh karena itu pelestarian budaya sangat di perlukan seiring berkembangnya teknologi yang semakin pesat. Media sosial adalah salah satu platform yang digunakan sebagai media promosi kepada masyarakat luas. Untuk menjaga budaya leluhur yang mulai punah. Penggunaan aplikasi editing foto digunakan untuk membuat kreasi foto yang menarik tentang budaya Saronen sebagai media promosi. Dengan memperkenalkan budaya Saronen melalui media sosial dengan foto yang menarik diharapkan akan mampu menarik minat masyarakat luas untuk ikut melestarikan budaya saronen yang diwariskan dari para leluhur. Maka, kami melalui program pengabdian akan melakukan pelatihan terhadap generasi muda sebagai pelaku budaya saronen untuk melakukan editing foto yang lebih menarik sebagai media promosi tentang budaya musik saronen yang nantinya akan dipublikasikan kepada masyarakat luas.
\end{abstract}

Kata kunci: Editing foto, Budaya musik, Saronen

\section{Pendahuluan}

Indonesia memiliki anugrah besar dalam hal kekayaan budayanya, Tercatat sebanyak 8065 budaya yang dimiliki oleh Indonesia. Oleh karena itu pelestarian budaya sangat di perlukan seiring berkembangnya teknologi yang semakin pesat. Budaya dapat diartikan sebagai bentuk cara hidup yang berkembang dan dimiliki oleh kelompok tertentu yang di wariskan dari generasi ke generasi. Saronen adalah salah satu budaya turun temurun yang diwariskan oleh lelulur dari masa ke masa khususnya daerah madura. Budaya saronen digunakan pada saat acara adat seperti arak arakan dan juga pada lomba kerapan sapi maupun lomba kecantikan sapi. Yang menarik dan menjadi jiwa dari musik ini satu alat tiup berbentuk kerucut, terbuat dari kayu jati dengan enam lubang berderet di depan dan satu lubang di belakang. Sebuah gelang kecil dari kuningan mengaitkan bagian bawah dengan bagian atas ujungnya terbuat dari daun siwalan. Pada pangkal atas musik itu ditambah sebuah sayap dari tempurung menyerupai kumis, menambah kejantanan dan kegagahan peniupnya. Alat tiup yg mengerucut ini berasal dari Timur Tengah yang dimodifikasi bunyinya. Pada perhelatan selanjutnya musik saronen ini dipakai untuk mengiringi lomba kerapan sapi, kontes sapi sono', upacara ritual, resepsi pernikahan, kuda serek ( kencak ) dll. (Hélène Bouvier. 2002) 


\section{Jcommdev}

JCommdev- JOURNAL OF COMMUNITY DEVELOPMENT \& EMPOWERMENT

Sebagai bentuk menjaga budaya, maka kolaborasi dengan kemajuan jaman sangat diperlukan. Dikarenakan pada era saat ini masyarakat tidak lepas dari teknologi. Khususnya generasi milenial. (Ardy Januantoro:2019). Untuk menjaga budaya leluhur yang mulai punah. Penggunaan media sosial sangat memungkinkan digunakan untuk menarik masyaraka luas (Ratnaningtyas YA, Widyasmoro A: 2016) agar tertarik mempelajari tentang budaya Saronen. Pada media sosial khususnya Instagram, kualitas foto sangat berpengaruh terhadap seberapa menarik foto itu untuk dilihat. Untuk mendapatkan foto yang menarik, ada beberapa cara yang dilakukan mulai dari Teknik pengambilan gambar, kualitas lensa dan editing foto. Pada kegiatan ini, kami melakukan pengabdian dengan bentuk pelatihan untuk memaksimalkan salah satu komponen untuk menjadikan foto lebih menarik dengan menggunakan aplikasi editing photo. Kami melakukan pelatihan bagaimana Teknik pencahayaan, gradasi warna dan teknik curve.

Pelatihan adalah suatu proses melatih; kegiatan atau pekerjaan (KBBI edisi 2, Balai Pustaka, 1989). Pelatihan mempersiapkan peserta latihan untuk mengambil jalur tindakan tertentu yang dilukiskan oleh teknologi dan organisasi tempat bekerja, dan membantu peserta memperbaiki prestasi dalam kegiatannya terutama mengenai pengertian dan keterampilan. (Rolf P. Lynton dan Udai Pareek:1998). Dalam pengartiannya, pelatihan terndapat beberapa macam pengartian seperti pendapat (Noe, Hollenbeck, Gerhart \& Wright (2003:251)) menjelaskan pelatihan merupakan suatu usaha yang terencana untuk memfasilitasi pembelajaran tentang pekerjaan yang berkaitan dengan pengetahuan, keahlian dan perilaku oleh para pegawai. Selain itu pendapat Gomez,dkk pelaksanaan pelatihan biasanya dilaksanakan pada saat para pekerja memiliki keahlian yang kurang atau pada saat suatu organisasi mengubah suatu system dan para perlu belajar tentang keahlian baru(Gomez-Mejia, Balkin, dan Cardy (2001:259)). Menurut Soekidjo Notoatmodjojo (1991: 53), pelaksanaan program pelatihan dapat dikatakan berhasil apabila dalam diri peserta pelatihan tersebut terjadi suatu proses transformasi dalam Peningkatan kemampuan dalam melaksanakan tugas dan Perubahan perilaku yang tercermin pada sikap, disiplin dan etos kerja.

Dengan adanya pelatihan ini, diharapkan hasil editing foto yang menarik tentang apa itu musik saronen akan mampu menarik minat masyarakat luas mempelajari apa itu musik tradisional Saronen. Sehingga nantinya masyarakan luas akan ikut melestarikan budaya saronen yang diwariskan oleh para leluhur.

\section{Metode Pelaksanaan}

Agar pelaksanaan program pengabdian masyarakat agar dapat terselesaikan dengan baik, maka dibuat beberapa tahapan untuk dijadikan sebagai pedoman dalam pelaksanaan program yaitu, pertama adalah pengkondisian situasi yang ada pada mitra agar membangun suasana kekeluargaan agar dapat saling bertukar pikiran untuk mengatasai permasalahan yang ada. Kedua, memberikan contoh - contoh publikasi yang sudah ada agar mitra dapat memiliki gambaran yang nanti akan bagaimana konten publikasi yang baik dan menarik. Ketiga, memberikan pelatihan kepada mitra yang bertujuan untuk memberikan edukasi kepada mitra tentang bagaimana mengatur warna, pencahayaan dan teknik editing lainnya. 


\section{int

Untuk pelaksaan program pengabdian memiliki nilai lebih pada mitra, maka aspek yang harus diperhatikan pada saat merealisasikan program pengabdian masyarakat ini yaitu: Pertama, mengedepankan aspek ergonomis yaitu pengabdi memberikan pemahaman kepada mitra pentingnya publikasi di dunia digital dalam upaya pelestarian budaya. Kedua, pemanfaatan aspek fungsional yaitu menjadikan mitra dapat mempunyai kemandirian dalam melakukan publikasi kegiatan yang ada pada pelaksanaan pelestarian budaya melalui ketrampilan teknis penggunaan aplikasi editing foto. Ketiga, memonitoring dan mengevaluasi pelaksaannya mulai dari pengkodisian lapangan sampai dengan publikasi digital.

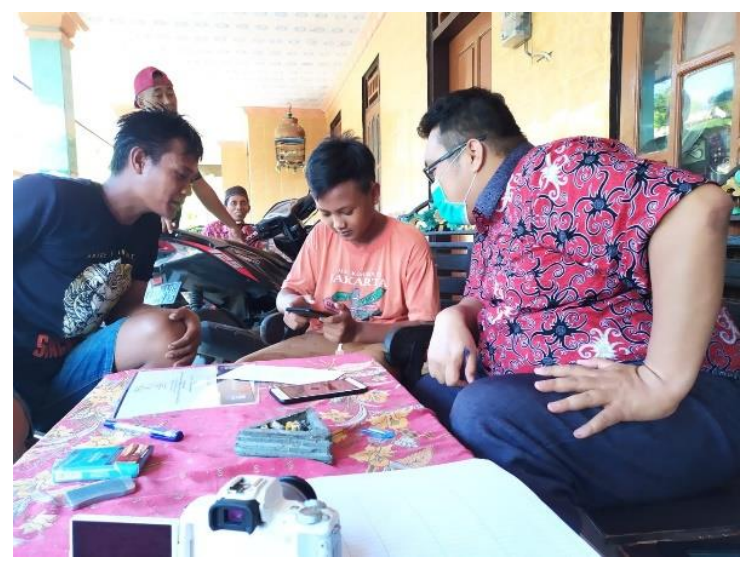

Gambar 1 Proses Pelatihan

Adapun tolak ukur keberhasilan program pengabdian ini dapat dilihat dari beberapa variabel yaitu pemahaman mitra mengenai teknik editing foto dan pemahaman mitra mengenai pentingnya publikasi digital dalam upaya pelestarian budaya, selesainya pembuatan buku panduan pembuatan konten publikasi kegiatan budaya, meningkatnya ketrampilan teknis dalam mengoperasikan dan memanfaatkan aplikasi editing foto untuk keperluan publikasi di sosial media.

Gambaran IPTEK yang diberikan oleh pengabdi kepada mitra melingkupi beberapa hal yaitu sosialisasi terhadap pentingnya pelestarian budaya yang mulai terlupakan oleh generasi muda, kemudian pembuatan buku panduan sebagai pegangan mitra secara tertulis agar mudah dalam memahami dan mempraktekkan pembuatan konten publikasi di media sosial.

Table 1 Supporting tim pengabdi

\begin{tabular}{|c||l||l||l|}
\hline No & \multicolumn{1}{|c||}{ Nama } & Bidang Keahlian & Supporting dalam Pelaksanaan \\
\hline \hline 1 & $\begin{array}{l}\text { Ardi Januantoro, S.Kom., } \\
\text { M.M.T }\end{array}$ & Teknik Informatika & • Pelatihan aplikasi editing foto \\
\hline \hline 2 & $\begin{array}{l}\text { Mohammad Insan } \\
\text { Romadhan, S.I.Kom., } \\
\text { M.Med.Kom. }\end{array}$ & $\begin{array}{l}\text { Komunikasi, Public } \\
\text { Relations \& Branding }\end{array}$ & • Proses sosialisasi kepada mitra \\
\hline \hline
\end{tabular}




\section{Jcommdev}

JCOmmdev- JOURNAL OF COMMUNITY DEVELOPMENT \& EMPOWERMENT

\section{Hasil dan Output}

Pada pelaksanaan program pengabdian masyakat yang dilakukan oleh pengabdi dalam memberikan pelatihan aplikasi editing foto guna mendukung pelestarian budaya kelompok musik Saronen, pengabdi melaksanakan tiga hal utama agar program pengabdian masyarakat dapat berjalan maksimal. Pertama adalah pembuatan buku panduan sebagai media panduan untuk membuat foto pada media sosial lebih menarik dengan menggunakan bahasa yang mudah dipahami dan diterima oleh pelaku musik saronen.

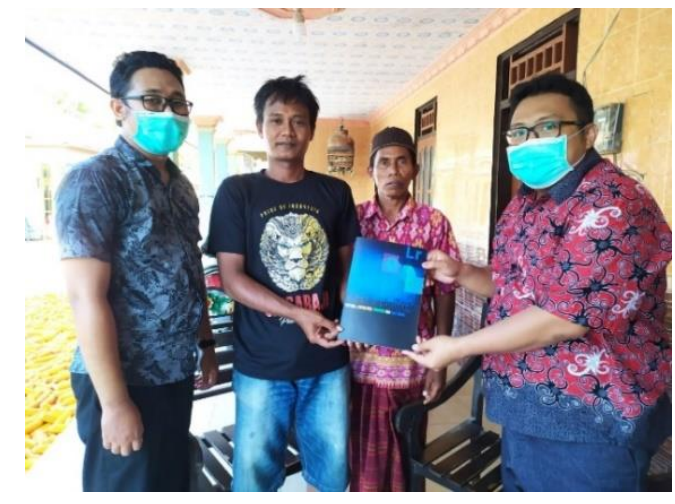

Gambar 2 Penyerahan buku panduan

Dengan adanya buku panduan maka mitra dapat mengaplikasikan teknik editing foto untuk membuat foto tampak lebih menarik dan elegan untuk di posting di media sosial. Adapun teknik yang dipelajari dalam buku panduan yaitu teknik pengaturan cahaya, teknik pengaturan warna dan komposisi, serta mengembangkan present yang sudah ada.

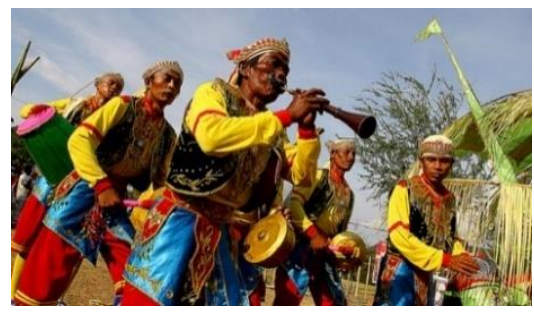

Sebelum

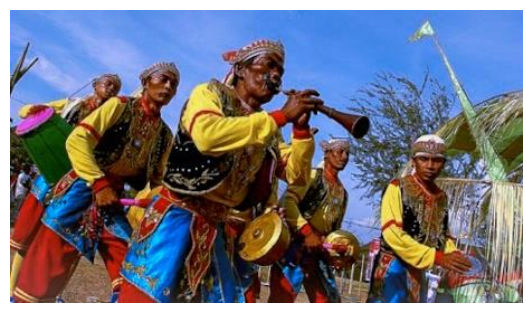

Sesudah

Gambar 3 hasil editing pelatihan dengan mitra

Dari hasil diatas terlihat perbedaan yang signifikan antara sebelum editing dan setelah editing. Yang paling terlihat jelas adalah pada pengaturan warna yang semakin cerah dan lebih hidup. Kemudian pencahayaan yang lebih segar. Kami juga melakukan survei terhadap tingkat pemahaman mitra tentang editing foto sebelum dan sesudah dilaksanakannya pelatihan. Hasil tersebut bisa dilihat pada gambar 3 . 


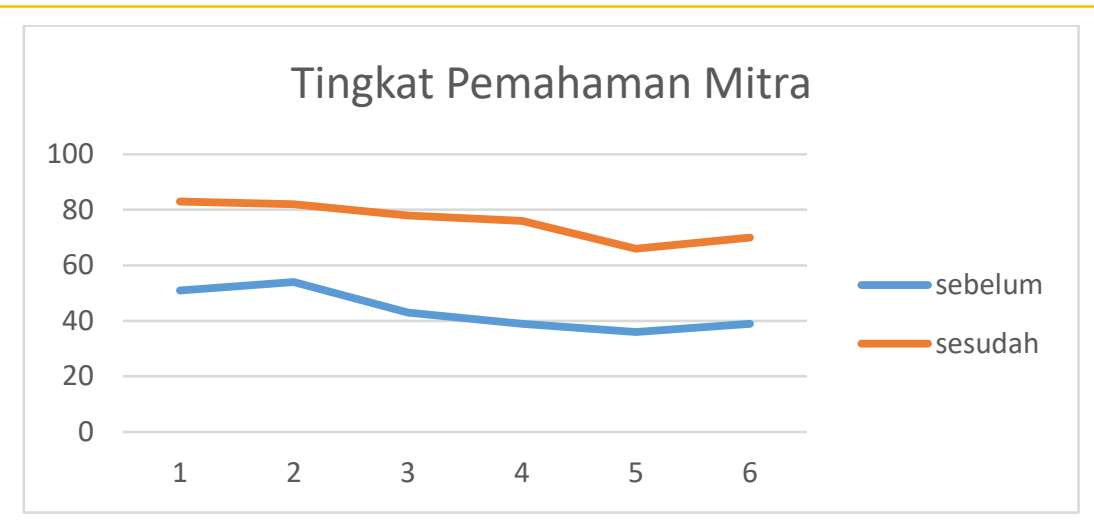

Gambar 4 hasil survei tingkat pemahaman mitra

Setelah penerapan teknik editing foto di praktekkan, maka mitra diberikan edukasi untuk memuat hasil editing ke media sosial sebagai sarana promosi salah satu budaya yang saat ini mulai punah.

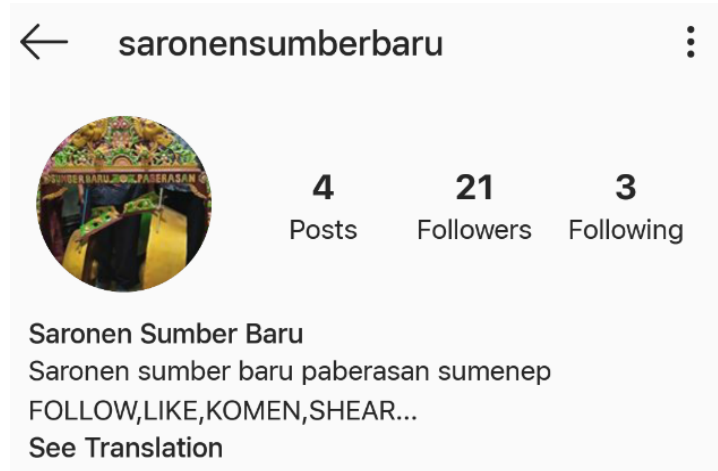

Gambar 4 hasil penerapan promosi budaya lewat media sosial

\section{Simpulan dan Saran}

Berdasarkan implementasi kegiatan pengabdian masyarakat dan evaluasi dengan mitra dapat disimpulkan bahwa (1)pelaksanaan kegiatan ini mampu menungkatkan pemahaman mitra untuk bagaimana pentingnya media sosial sebagai sarana promosi,(2) membuat mitra mampu mengaplikasian teknik editing foto untuk memaksimalkan hasil foto yang akan di publikasi, (3) memberikan sarana akun media sosial sebagai sarana untuk mempromosikan budaya Saronen kepada masyarakat luas.

Berdasarkan evaluasi yang telah dilakukan dapat diajukan beberapa saran yaitu: (1) mitra diharapkan lebih mengeksplore teknik - teknik yang lebih terbaru untuk menambah wawasan, (2) mitra diharapkan aktif di media sosial untuk memberikan info, foto kegiatan, dan jadwal kegiatan secara up to date. 


\section{Daftar Pustaka}

Ardy Januantoro, Mohammad Insan Romadhan, 2019, LITERASI MEDIA “EDUKASI MENDETEKSI BERITA HOAX” BERBASIS GAME ANDROID PADA SISWA SMP NEGERI 7 SURABAYA, Jurnal LEECOM

Gomez-Mejia, Balkin, Cardy, 2001, Managing Human Resources, International Edition, Prentice Hall, Inc.,New Jersey

Hélène Bouvier. 2002. Lèbur: seni musik dan pertunjukan dalam masyarakat Madura. Yayasan Obor Indonesia. ISBN 979-461-420-3, 9789794614204

Kamus Besar Bahasa Indonesia edisi 2, Balai Pustaka, 1989

Moloeng, Lexy. 2002. Metodologi Penelitan Kualitatif. Bandung: Remaja Rosdakarya.

Noe, Hollenbeck, Gerhart, Wright, 2003, Human Resource Management, International Edition, The McGraw-hill Companies, Inc. New York

Ratnaningtyas YA, Widyasmoro A. 2016. Pemasaran Desa Wisata Kalibuntung dalam Mendukung Pengembangan Pariwisata di Kabupaten Bantul. Jurnal Kepariwisataan Indonesia [internet]. [Diunduh: 9 Maret 2017]. Vol 11 (1): 1-23.

Romadhan, M. I., Puspaningtyas, A., Rahmadanik, D. (2019). "Proses Komunikasi Dalam Pelestarian Budaya Saronen Kepada Generasi Muda". Jurnal Pikom: Penelitian Komunikasi dan Pembangunan. Vol. 20(01), hal: 1-12. 